\title{
Extensive Coronary Thrombus in Patients Presenting with STEMI and COVID-19 Infection
}

\author{
Angela Li, MD* (iD, Calvin Ngai, MD ${ }^{(D)}$, Loukas Boutis, MD and Bani M Azari, MD, PhD \\ Department of Cardiology, Donald and Barbara Zucker SOM at Hofstra/Northwell, North Shore University \\ Hospital, USA
}

*Corresponding author: Angela Li, MD, Department of Cardiology, Donald and Barbara Zucker SOM at Hofstra/Northwell, Sandra Atlas Bass Heart Hospital, North Shore University Hospital, 300 Community Drive, 1 Cohen, Manhasset, NY 11030, USA, Tel: 201-486-0920

\begin{abstract}
The pathophysiology of ST-elevation myocardial infarction (STEMI) is not well understood in Coronavirus disease 2019 (COVID-19). We present similar angiographic findings in two COVID-19 patients with STEMI. Despite percutaneous coronary intervention $(\mathrm{PCl})$, distal coronary flow was not restored. The pro-thrombotic and inflammatory effects of COVID-19 may lead to myocardial infarction.
\end{abstract}

\section{Keywords}

Percutaneous coronary intervention, Acute coronary syndrome, Cardiovascular disease, Coronary angiography, Echocardiography, Myocardial infarction

\section{Abbreviations}

STEMI: ST-Elevation Myocardial Infarction; COVID-19: Coronavirus Disease 2019; $\mathrm{PCl}$ : Percutaneous Coronary Intervention; CAD: Coronary Artery Disease; SARS-CoV2: Severe Acute Respiratory Syndrome Coronavirus 2; $\mathrm{SpO}_{2}$ : Peripheral Oxygen Saturation; ECG: Electrocardiogram; RCA: Right Coronary Artery; LAD: Left Anterior Descending Artery; TTE: Transthoracic Echocardiogram

\section{Introduction}

The COVID-19 pandemic has caused a significant strain on global healthcare systems. STEMI management during this time has similarly been affected. Preliminary findings show a $38 \%$ decrease in STEMI activations in catheterization laboratories across the United States [1]. Additionally, there has been a significant increase in out of hospital cardiac arrest [2]. Of the STEMI cases that have been reported, there is an increased incidence of acute thrombosis noted during initial cath- eterization and after intervention, often attributed to increased inflammation and platelet aggregation [3,4]. We present here two COVID-19 patients with STEMI who were found with significant coronary thrombus not amenable to $\mathrm{PCl}$.

\section{Case Series}

\section{Case 1}

A 65-year-old male with history of hypertension and diabetes presented to the emergency department with chest pain and shortness of breath for 3 days. 10 days prior to presentation, he developed fevers, cough, and extreme body aches for which he tested positive for severe acute respiratory syndrome coronavirus 2 (SARSCoV2) at an urgent care center.

His symptoms initially improved, then on day 7 developed new escalating chest pain prompting presentation to the hospital. On arrival, he was afebrile with a blood pressure of 103/63 and heart rate of 40 beats per minute. His peripheral oxygen saturation $\left(\mathrm{spO}_{2}\right)$ was $96 \%$ breathing room air. Physical exam was remarkable for bradycardia and clear bilateral lung fields.

Laboratory values were significant for elevated high sensitivity troponin T to $4397 \mathrm{ng} / \mathrm{L}, \mathrm{C}$-reactive protein of $24.32 \mathrm{mg} / \mathrm{dL}$, ferritin of $1739 \mathrm{ng} / \mathrm{mL}$, and D-Dimer of $317 \mathrm{ng} / \mathrm{mL}$. Electrocardiogram (ECG) revealed sinus bradycardia with complete heart block and inferior ST-segment elevations (Figure 1). He was loaded with aspirin, ticagrelor and unfractionated heparin bolus prior to emergent catheterization.

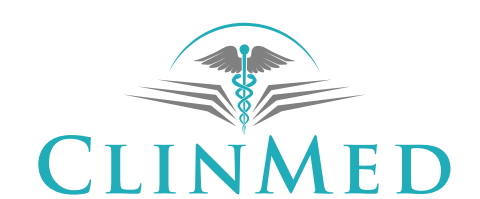

INTERNATIONAL LIBRARY
Citation: Li A, Ngai C, Boutis L, Azari BM (2020) Extensive Coronary Thrombus in Patients Presenting with STEMI and COVID-19 Infection. Int J Clin Cardiol 7:195. doi.org/10.23937/2378-2951/1410195 Accepted: August 11, 2020; Published: August 13, 2020

Copyright: (C) 2020 Li A, et al. This is an open-access article distributed under the terms of the Creative Commons Attribution License, which permits unrestricted use, distribution, and reproduction in any medium, provided the original author and source are credited. 


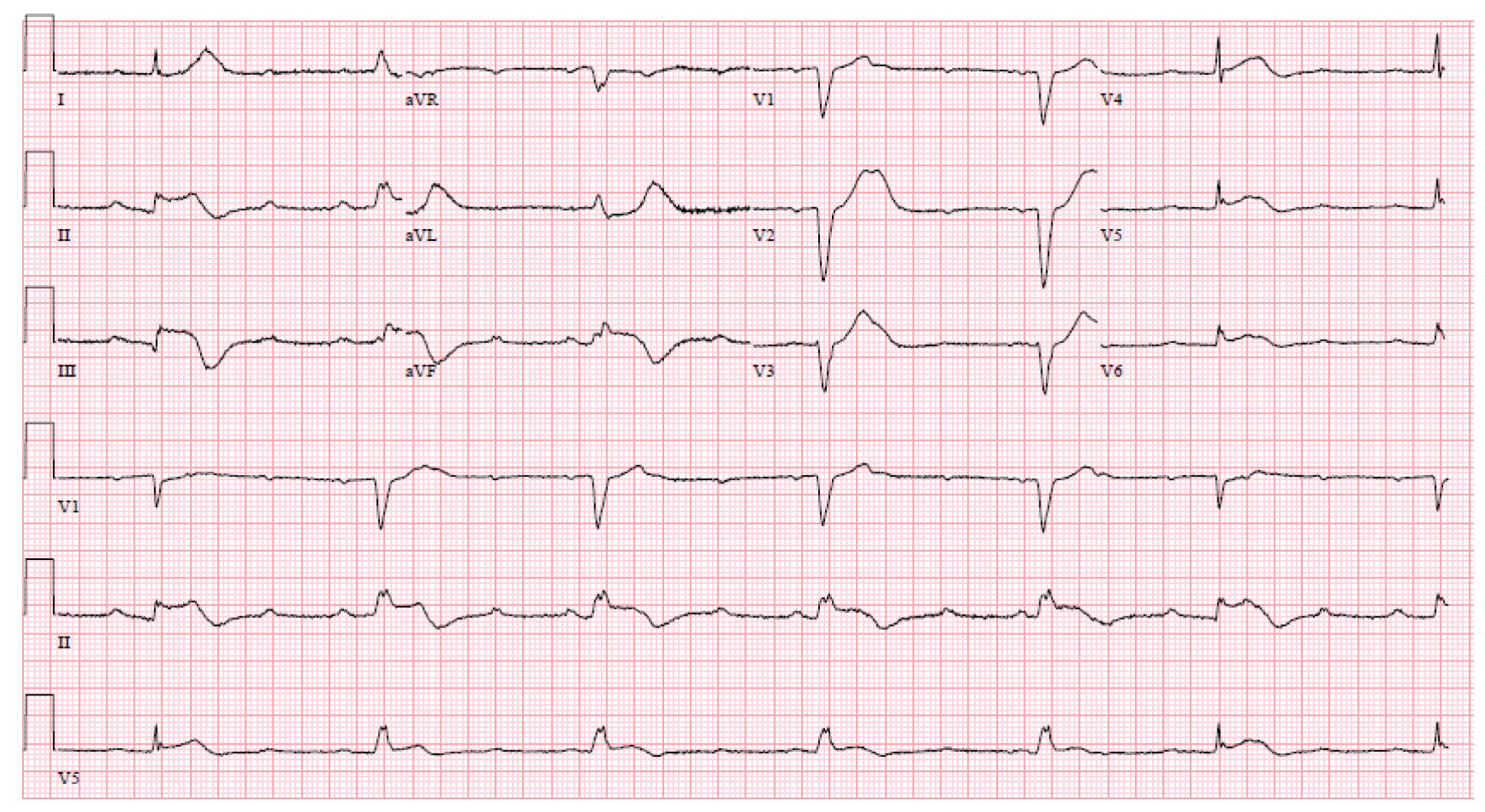

Figure 1: ECG shows inferior STEMI with complete heart block and slow ventricular escape rhythm.

A

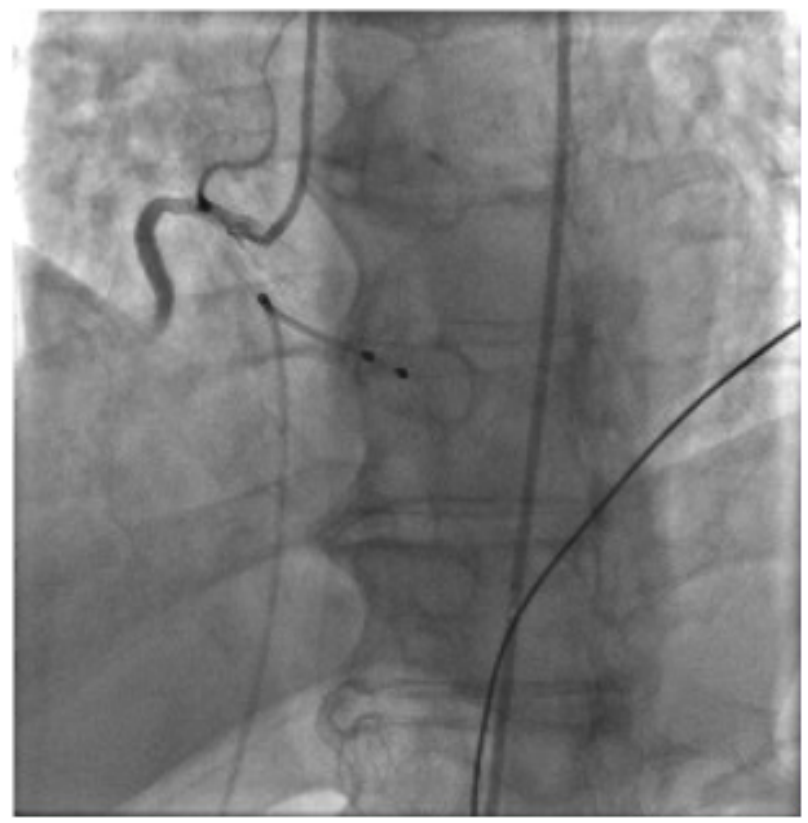

B

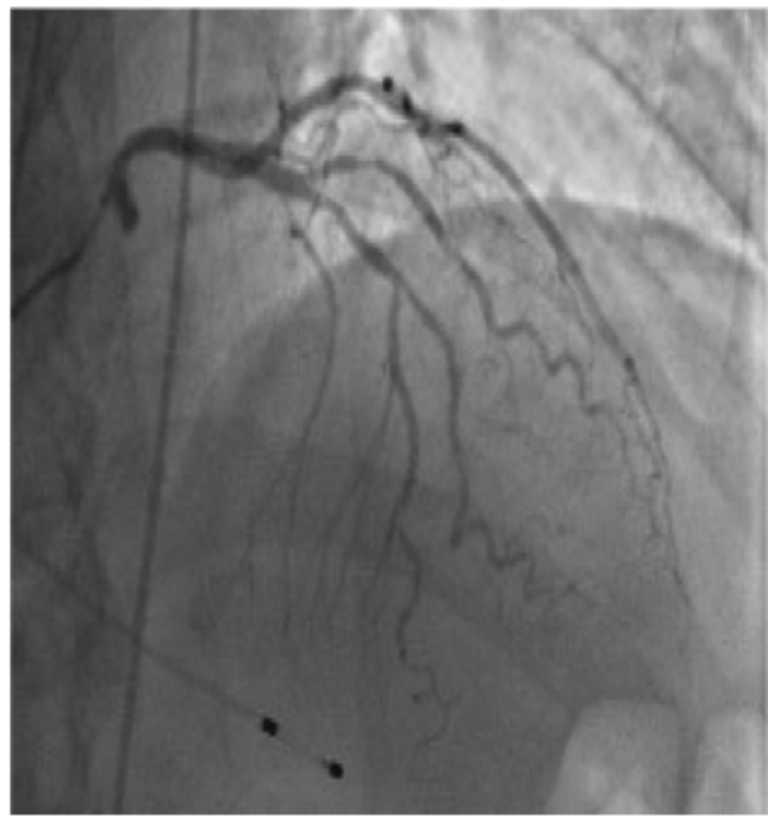

Figure 2: (A) Coronary angiography showing mid-RCA 100\% occlusion; (B) Moderate LAD disease.

Cardiac catheterization showed $100 \%$ mid right coronary artery (RCA) stenosis as well as moderate disease in the left anterior descending artery (LAD) (Figure 2 and Video 1). The decision was made to perform $\mathrm{PCl}$ of the RCA lesion; however, despite thrombectomy, balloon angioplasty, stenting, and intracoronary vasodilators and glycoprotein IIb/IIla inhibitors, there was TIMI flow 0 (Figure 3, Video 2 and Video 3). Intravascular ultrasound was performed to assess stent expansion and the distal coronary vessel. The epicardial vessel visualized distal to the stent was patent with mild atherosclerosis, with no visible edge dissection. It was determined the distal coronary bed could not regain flow due to persistent microvascular thrombus and occlusion. An intra-aortic balloon pump was placed prior to transfer to intensive care unit and an eptifibatide infusion was continued for 18 hours.

Patient remained hypotensive after procedure with concern for cardiogenic shock. Transthoracic echocardiogram (TTE) confirmed severe hypokinesis in RCA distribution of the inferior wall and right ventricular dysfunction, but also in the LAD territory with hypokinesis of the apical and septal walls with an ejection fraction 


\section{A}

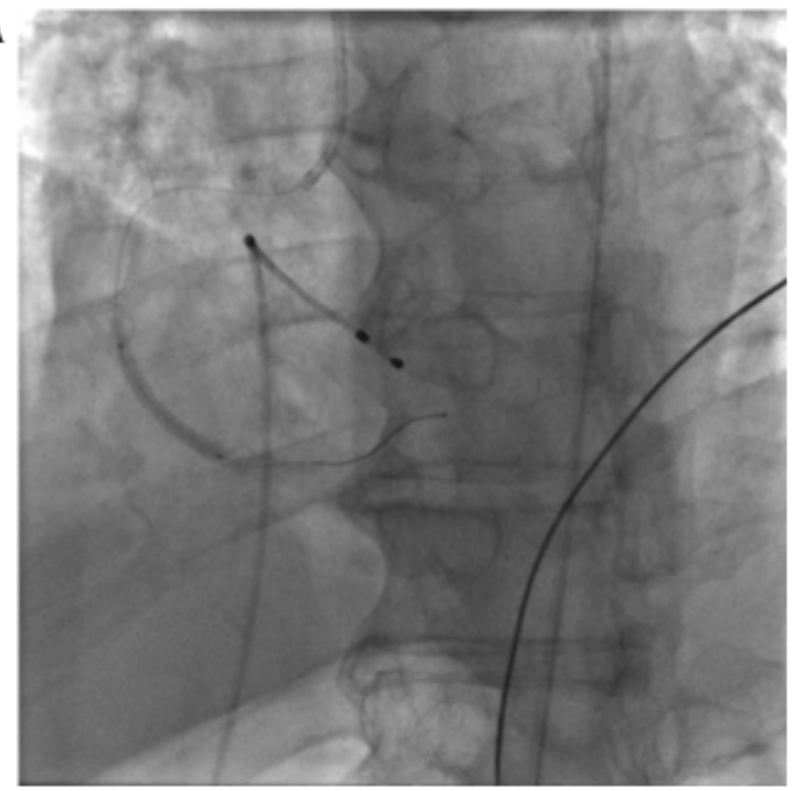

B

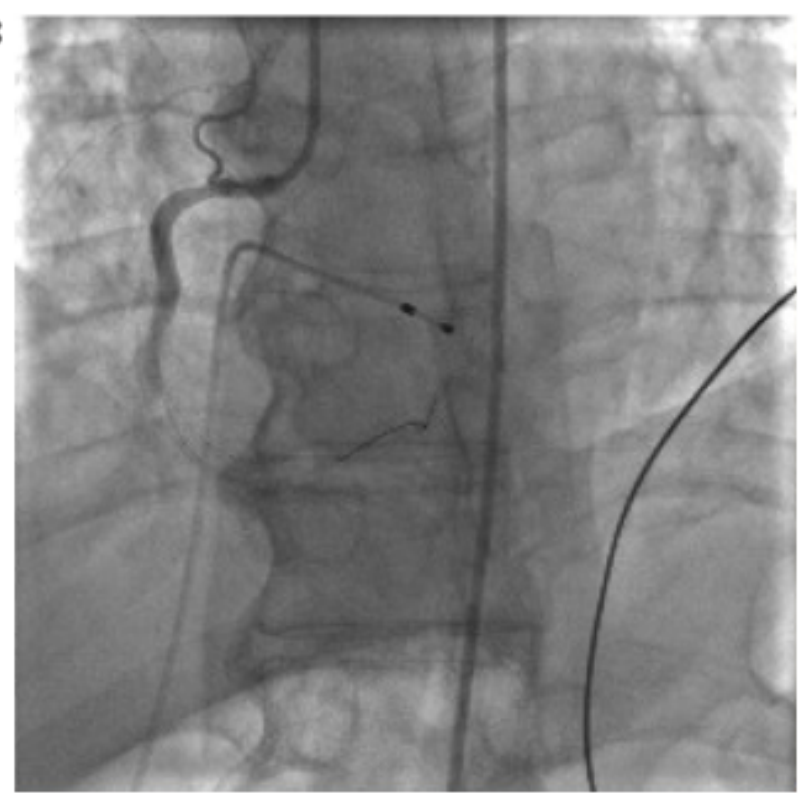

Figure 3: (A) Coronary angiography of $\mathrm{PCl}$; (B) Coronary angiography with continued poor distal flow after thrombectomy, $\mathrm{PCl}$ and intracoronary vasodilators.
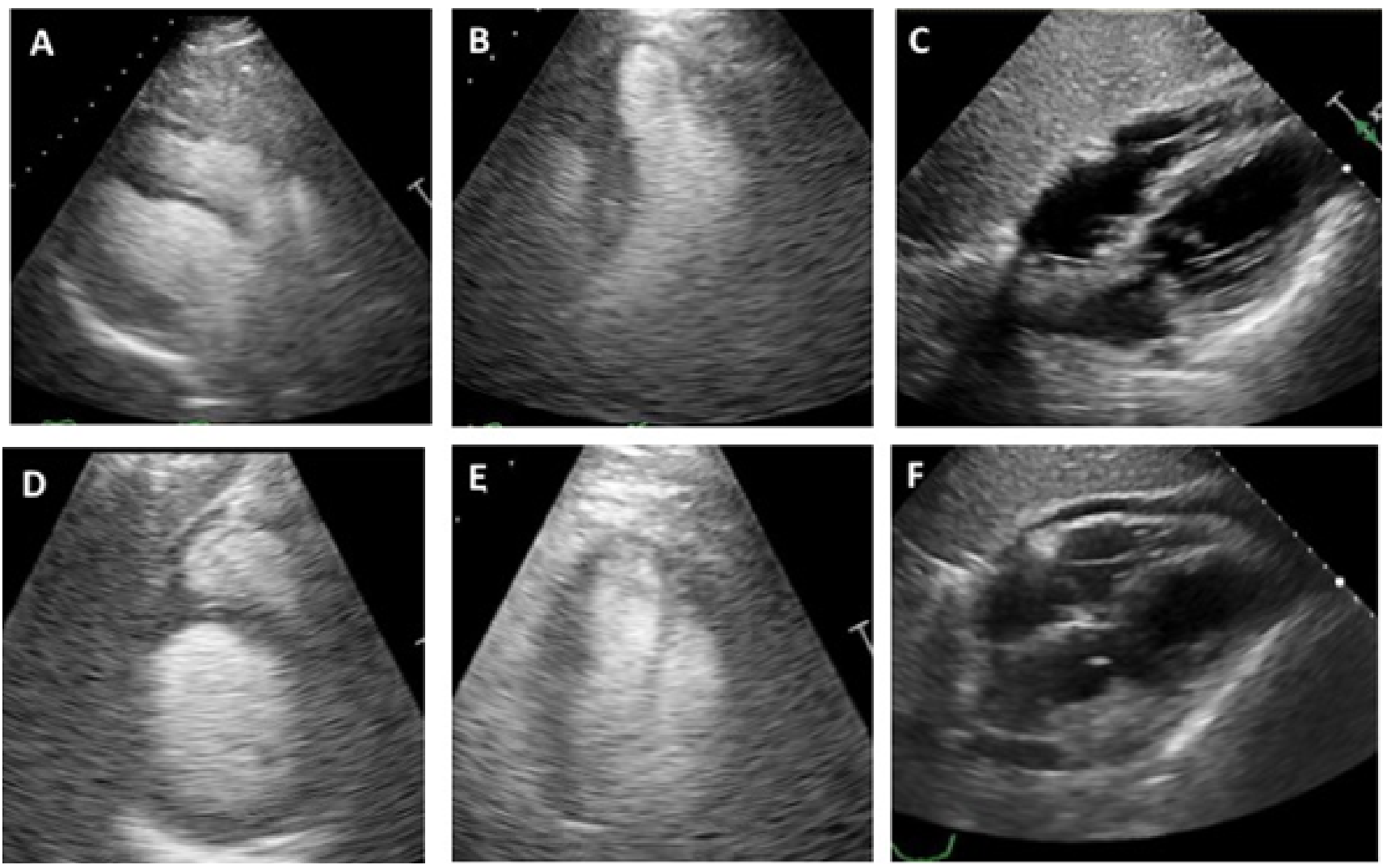

Figure 4: (A) TTE in parasternal long axis view; (B) 4-chamber view; (C) Subcostal view; (D) Short axis view; (E) 2-chamber view; (F) Follow-up TTE with new pericardial effusion.

of $20-25 \%$ (Figure 4). He was started on dobutamine infusion but experienced further clinical deterioration. Repeat TTE showed no changes but a small pericardial effusion without hemodynamic significance (Figure 4). A Swan-Ganz catheter was placed with a cardiac index of $1.9 \mathrm{~L} / \mathrm{min} / \mathrm{m}^{2}$. Patient was deemed to be a poor candidate for further advanced mechanical support. Despite increasing pressor and inotropic support, he passed away on day 7 of hospital admission.

\section{Case 2}

A 74-year-old female with history of hypertension, diabetes, hyperlipidemia, and coronary artery disease (CAD) presented to an outside hospital with shortness of breath, fevers, and myalgias for 3 days. On arrival, she was afebrile with a blood pressure of 129/44 and 


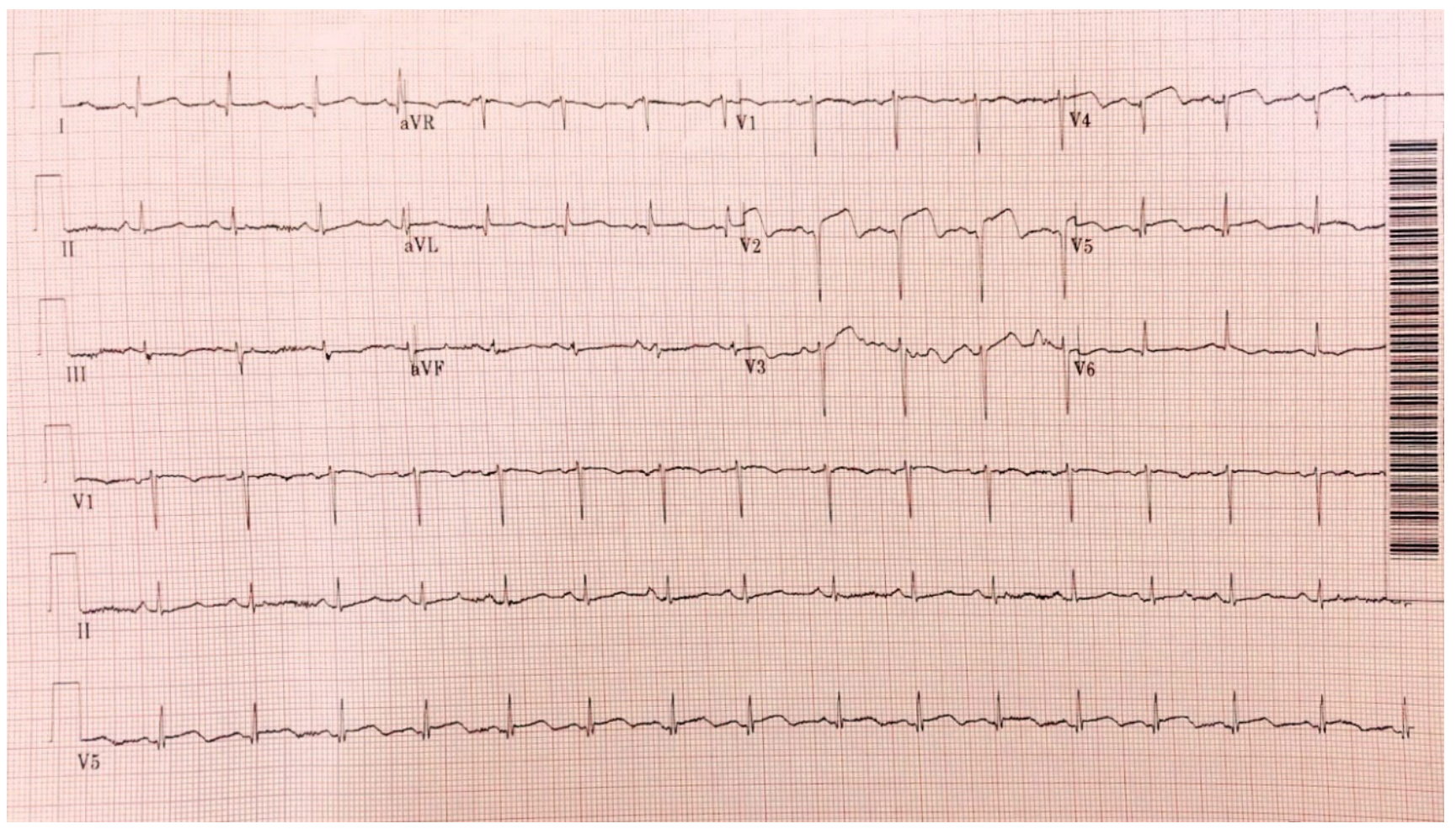

Figure 5: ECG shows anterolateral STEMI.

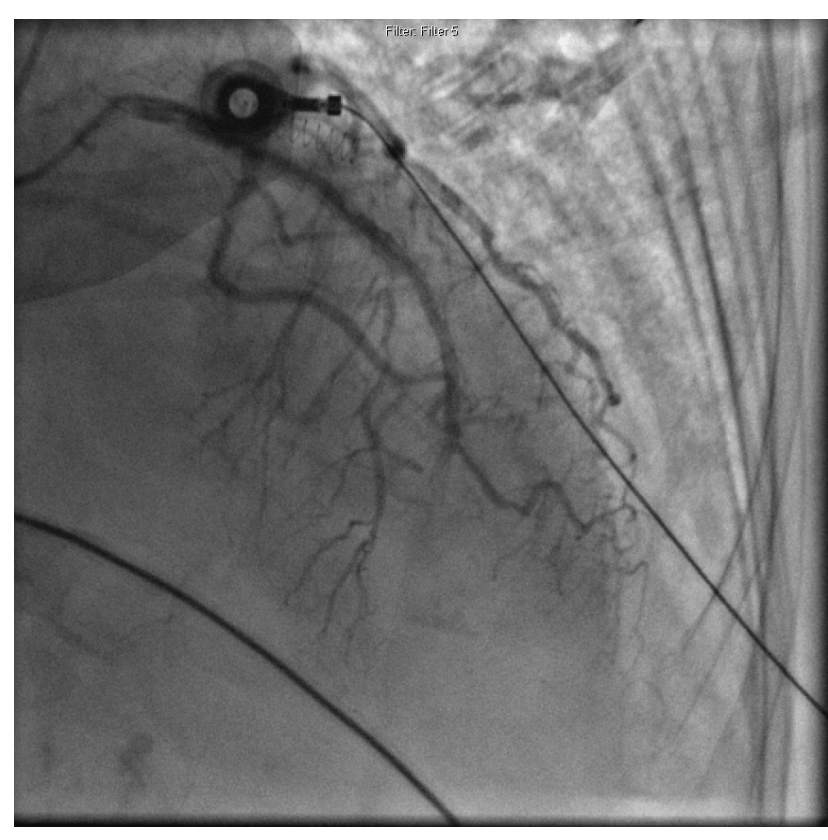

Figure 6: Coronary angiography showing distal LAD 100\% occlusion.

heart rate of 85 beats per minute. $\mathrm{Her} \mathrm{spO}_{2}$ was $51 \%$ breathing room air, which improved on non-rebreather mask. Physical exam was notable for tachycardia, tachypnea, and coarse breath sounds in the bilateral lung fields. Chest X-ray showed diffuse bilateral patchy opacities.

Laboratory values were significant for positive SARSCoV2 by Real Time Reverse Transcriptase Polymerase Chain Reaction, normal high sensitivity troponin $\mathrm{T}$ of 11 $\mathrm{ng} / \mathrm{L}$, elevated C-reactive protein of $152.9 \mathrm{mg} / \mathrm{dL}$, fer- ritin of $2804 \mathrm{ng} / \mathrm{mL}$, and D-Dimer of $3903 \mathrm{ng} / \mathrm{mL}$. She was admitted for management of hypoxic respiratory failure due to COVID-19 infection. 5 days into her hospital course, she developed new onset chest pain. Repeat high sensitivity troponin T was $782 \mathrm{ng} / \mathrm{L}$ and ECG showed new anterolateral ST-segment elevations (Figure 5). She was loaded with aspirin, clopidogrel and therapeutic enoxaparin, and electively intubated for transport to our facility for urgent cardiac catheterization.

Cardiac catheterization showed $100 \%$ distal LAD lesion (Figure 6 and Video 4). Thrombectomy and PCI of the LAD lesion was performed with balloon angioplasty and stent placement but distal flow could not be achieved (Figure 7, Video 5 and Video 6). TTE post procedure showed mild segmental left ventricular systolic dysfunction with hypokinesis of the apex with an ejection fraction of $45 \%$ (Figure 8). She was transferred to the intensive care unit for further care.

Patient's hospital course following catheterization was complicated by development of acute respiratory distress syndrome requiring paralysis and multiorgan dysfunction requiring pressor support. Repeat TTE one day after $\mathrm{PCl}$ demonstrated no changes but a new organized pericardial effusion (Figure 8). Patient continued to clinically deteriorate with septic shock and worsening oxygenation due to superimposed bacterial pneumonia and bacteremia. She had no neurologic function while intubated off of sedation, and brain imaging diagnosed a large ischemic stroke without hemorrhagic conversion in the posterior cerebral artery distribution. Despite maximum medical support, patient expired on hospital day 20 from sepsis and respiratory failure. 
A

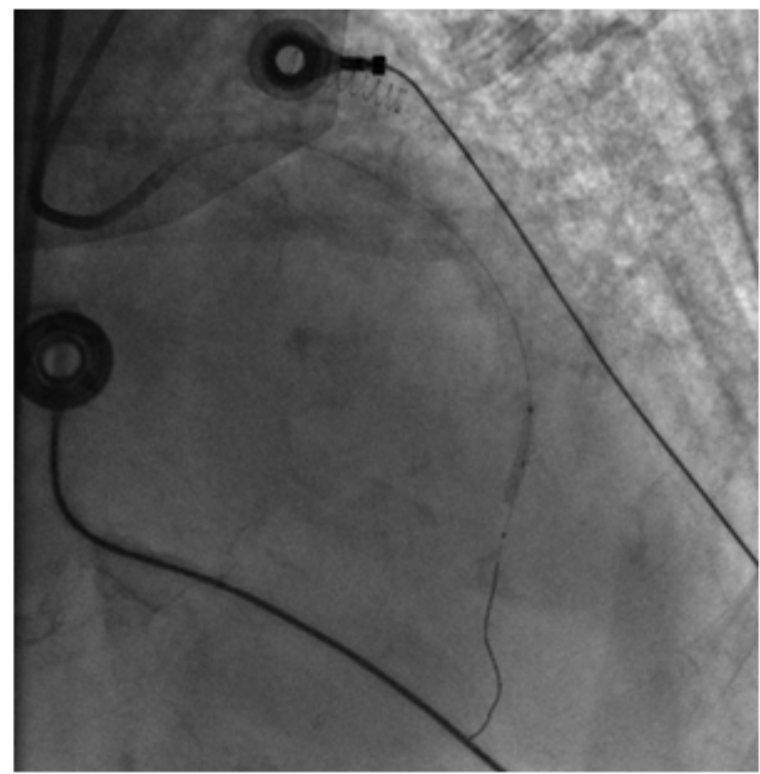

B

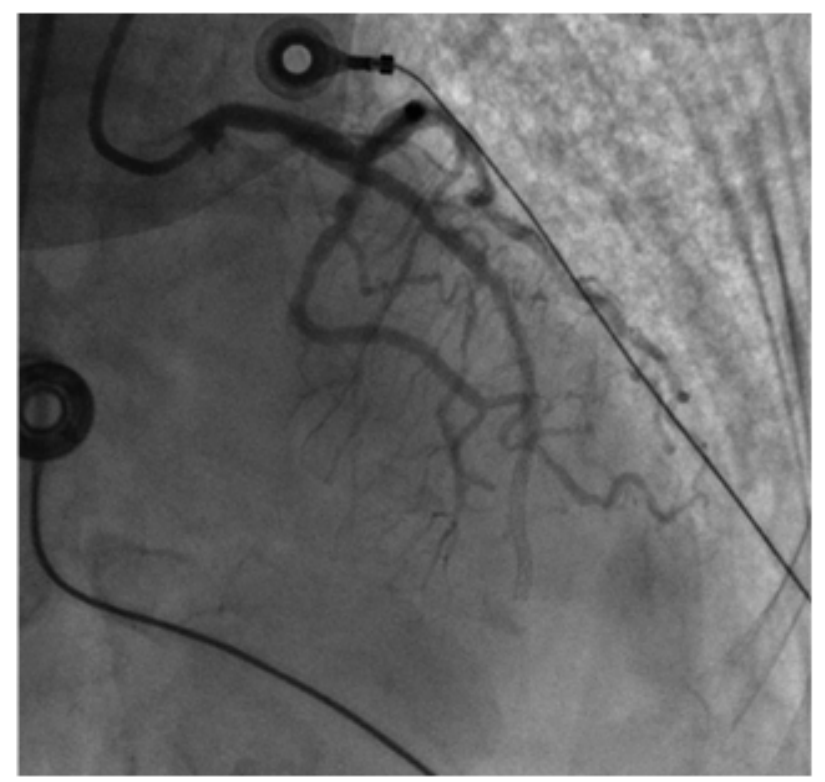

Figure 7: (A) Coronary angiography of $\mathrm{PCl}$; (B) Coronary angiography with continued poor distal flow after thrombectomy and $\mathrm{PCl}$.
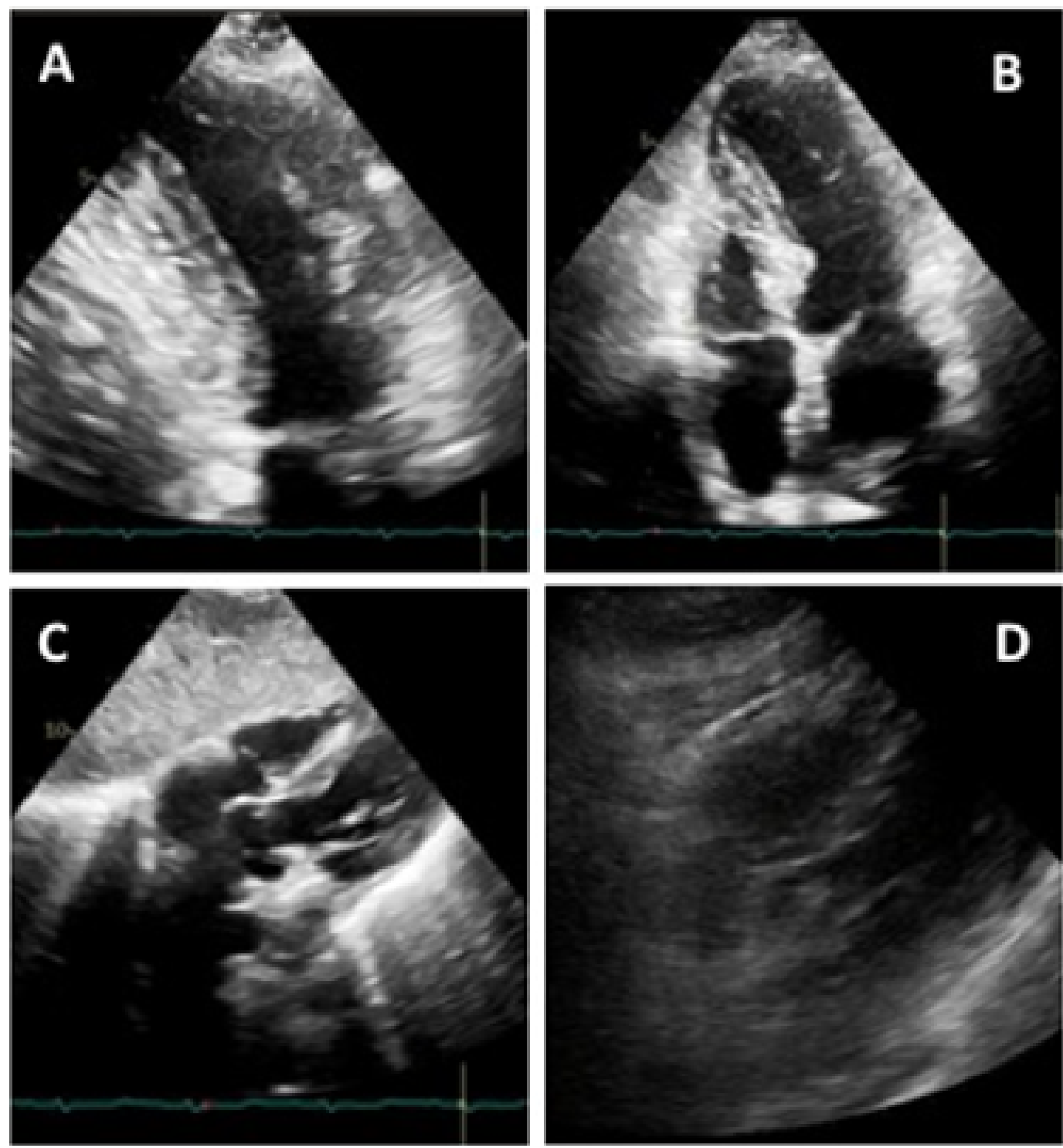

Figure 8: (A) TTE in 2-chamber view; (B) 4-chamber view; (C) Subcostal view; (D) Repeat TTE in subcostal view with a new organized pericardial effusion. 


\section{Discussion}

Optimal treatment for COVID-19 is actively under investigation. Primary $\mathrm{PCl}$ remains the standard of care for STEMI in patients with confirmed or suspected COVID with proven superiority in revascularization over fibrinolysis [5]. There is increased prevalence of STEMI mimickers associated with COVID-19, with one case study that found a third of COVID patients with ST-segment elevation had nonobstructive coronary disease [6]. There has been increasing research into the pathogenesis of COVID-19 related thrombotic disease, thought to be the result of uninhibited inflammatory response, sequalae of severe illness, and direct viral interaction with ACE2 receptors [7]. The increased incidence of arterial thrombosis in COVID-19 myocardial infarction has been noted in case series reports [8], and has been observed in other similar respiratory virus outbreaks [9]. Microvascular coagulopathy has also been observed as part of the disease spectrum [10], which may additionally contribute to severe myocardial dysfunction in patients with and without obstructive CAD [6].

Our case series highlights the interplay of all contributing factors mentioned above. Our patients presented with STEMI in the setting of COVID-19 infection with elevated inflammatory and coagulopathy levels, and were found to have insurmountable coronary thrombosis despite appropriate antiplatelet therapy, full anticoagulation and multiple modalities of coronary intervention. The finding of no-reflow or TIMI grade 0 flow following $\mathrm{PCl}$ supports the presence of microvascular thrombosis with capillary obstruction and potential myocardial edema present at the time of the STEMI, and may directly result from COVID-19 infection. Both patients presented with STEMI around 5-7 days following COVID-19 symptom onset, during a period recognized for heightened inflammation or cytokine storm. Reperfusion without flow restoration to downstream capillary bed is an independent predictor of adverse outcomes of acute $\mathrm{MI}$ [11].

Therefore, patients presenting with STEMI during cytokine storm phase of COVID-19 infection should be recognized as having potential for poor revascularization despite $\mathrm{PCl}$ and potentially worse outcomes than other STEMI patients.

\section{Conclusion}

In-hospital and 1 year mortality rates for STEMI have decreased significantly in the past decade, with implementation of guidelines for appropriate medical therapy and timely $\mathrm{PCl}$ [12]. The current viral outbreak highlights new challenges to such care. Increased coronary thrombotic burden may be seen during coronary interventions that are not amenable to $\mathrm{PCl}$. Clinicians should recognize that COVID-19 patients presenting with STEMI during cytokine storm may have extensive macrovascular as well as microvascular thrombosis and that this may lead to subsequent poor revascularization.

\section{Author Contributions}

Angela Li (equal role in conceptualization, lead role in data curation, writing, review and editing); Calvin Ngai (supporting role in data curation, writing, review and editing); Loukas Boutis (supporting role in supervision, review and editing); Bani M Azari (equal role in conceptualization, lead role in supervision, supporting role in data curation, writing, review and editing).

\section{Funding}

No grant or institutional funding was involved in this case report.

\section{Disclosure Statement}

All authors have no conflicts of interest to disclose.

The Northwell Health Institutional Review Board approved this case series as minimal-risk research using data collected for routine clinical practice and waived the requirement for informed consent.

\section{Acknowledgement}

We would like to acknowledge the contributions of the Northwell Health COVID-19 Research Consortium.

\section{References}

1. Garcia S, Albaghdadi MS, Meraj PM, Schmidt C, Garberich $R$, et al. (2020) Reduction in ST-segment elevation cardiac catheterization laboratory activations in the United States during COVID-19 pandemic. J Am Coll Cardiol 75: 28712872.

2. Baldi E, Sechi GM, Mare C, Canevari F, Brancaglione A, et al. (2020) Out-of-hospital cardiac arrest during the Covid-19 outbreak in Italy. N Engl J Med 383: 496-498.

3. Lacour T, Semaan C, Genet T, Ivanes F (2020) Insights for increased risk of failed fibrinolytic therapy and stent thrombosis associated with COVID-19 in ST-segment elevation myocardial infarction patients. Catheter Cardiovasc Interv.

4. Yolcu M, Gunesdogdu F, Bektas M, Bayirli DT, Serefhanoglu K (2020) Coronavirus disease 2019 (COVID-19) and simultaneous acute anteroseptal and inferior ST-segment elevation myocardial infarction. Cardiovasc J Afr 31: 1-4.

5. Mahmud E, Dauerman HL, Welt FGP, Messenger JC, Rao SV, et al. (2020) Management of acute myocardial infarction during the COVID-19 pandemic. J Am Coll Cardiol.

6. Bangalore S, Sharma A, Slotwiner A, Yatskar L, Harari R, et al. (2020) ST-Segment elevation in patients with Covid-19A case series. N Engl J Med 382: 2478-2480.

7. Liu PP, Blet A, Smyth D, Li H (2020) The science underlying COVID-19: Implications for the cardiovascular system. Circulation 142: 68-78.

8. Klok FA, Kruip MJHA, van der Meer NJM, Arbous MS, Gommers DAMPJ, et al. (2020) Incidence of thrombotic complications in critically ill ICU patients with COVID-19. Thromb Res 191: 145-147.

9. Bikdeli B, Madhavan MV, Jimenez D, Chuich T, Dreyfus I, et al. (2020) COVID-19 and thrombotic or thromboembolic 
disease: Implications for prevention, antithrombotic therapy, and follow-up. J Am Coll Cardiol 75: 2950-2973.

10. Magro C, Mulvey JJ, Berlin D, Nuovo G, Salvatore S, et al. (2020) Complement associated microvascular injury and thrombosis in the pathogenesis of severe COVID-19 infection: A report of five cases. Transl Res 220: 1-13.

11. Morishima I, Sone T, Okumura K, Tsuboi H, Kondo J, et al. (2000) Angiographic no-reflow phenomenon as a predictor of adverse long-term outcome in patients treated with per- cutaneous transluminal coronary angioplasty for first acute myocardial infarction. J Am Coll Cardiol 36: 1202-1209.

12. O'Gara Patrick T, Kushner Frederick G, Ascheim Deborah D, Casey Donald E, Chung Mina K, et al. (2013) 2013 ACCF/AHA guideline for the management of ST-Elevation myocardial infarction: A report of the American College of Cardiology Foundation/American Heart Association Task Force on Practice Guidelines. Circulation 127: e362-e425. 